Doi: https://doi.org/10.31578/jebs.v6i2.242

\title{
Teacher Opinions and Perspectives of Visual Culture Theory and Material Culture Studies in Art Education
}

\author{
Rasim Basak*
}

\begin{abstract}
Teacher opinions and discussions about Visual Culture Theory and Material Culture in art education are examined in this paper. Both approaches were compared and evaluated within their contents and fundamentals. Visual Culture Art Education (VCAE) in art education, specifically, has been criticized as having a Neo-Marxist or Cultural Marxist agenda stemming from Critical Theory, nonetheless, it is also viewed as being just another recent Postmodernist approach. Being a controversial theoretical account, VCAE seems widely unknown and not understood in its conceptual frame among art teachers in Turkey. Its name also may have caused confusions. In this study, art teacher opinions of VCAE content, principles, applications and practices were collected through a survey questionnaire; and examined. Participants were 71 art teachers. Purposeful, convenient, random sampling method was employed to represent a population of art teachers from various backgrounds, with various experience levels, with educational experience from various universities, working at various geographical regions and towns in Turkey. The study was designed and structured as a descriptive survey research. Analyses revealed that art teachers usually are not aware of the typical discussions about VCAE. Having been criticized as an ideologically rooted theory, applicability of VCAE in Turkey seems controversial in many aspects.
\end{abstract}

Key words: visual culture, Modernism, DBAE, VCAE, critical pedagogy, Postmodernism, neo-marxism

\section{Introduction}

Visual Culture Theory (Visual Culture Art Education, VCAE) is rooted back to the Cultural Studies, which emerged during the 1960s in England. Cultural Studies were based on shared experiences and structural dynamics of modern society. They relied on power dynamics structured around or maintaining the status quo and their structural influences in the society. Cultural Studies started as a literacy theory at the beginning but later influenced other fields such as sociology, psychology, feminist studies, media studies and art history (Duncum, 2003). A more recent discipline, Visual Culture Studies, emerged around the 1990s. It was based on Critical Approach (Duncum, 2003, p. 19). Chalmers (2005) explained that VCAE rooted back to June King McFee, who for the first time used the words 'visual' and 'culture' together in the book titled 'Preparation for Art' in 1961. Even though McFee did not have the power to make a difference in the highly conservative 1940s and 1950s, she was well aware that changing popular cultural atmosphere and cultural conditions required new understandings and approaches in education, and that studies required the diversity of values reflected through media in American society. In addition, she pointed out that art teachers should not have been limited to TV and movies, but should take buildings, clothes, decorations, advertisements, posters, cartoons and other diverse popular media and their meanings into consideration. Social media is increasingly becoming a new tool for cultural

\footnotetext{
* Ph.D., Associate Professor, Department of Art Education, School of Education, Uludag University, Bursa, Turkey Corresponding Email: rasimbasak@gmail.com
} 
reproduction and enculturation process (Chalmers, 2005, p. 7). Thereupon, she suggested new teaching strategies to teach critical thinking. The idea of change, on the other hand, is not a new concept, for over a century academicians have been working on inclusive models regarding new industrial production process and teaching students about the new media (Chalmers, 2005).

The 1960s were a new era and a breaking point, in which movies and TV were introduced as new study areas at universities. Art Sociology was founded in the 1960s and later evolved into Cultural Studies discipline. A need for teaching cultural symbols, heritage, and iconography as part of curriculum in art education was voiced in 1967 by Mary-Lou Kuhn (Chalmers, 2005, p. 10). We could say that the visual cultural approach was already starting to emerge in the 1960s; nevertheless, it was not a systematic educational paradigm yet. Barnard explained theoretical fundamentals of visual culture studies as follows:

People exist in positions of unequal power and status and visual culture may be thought of as the ways in which that structure of inequalities is first made possible and then either continued or contested. These positions of power and status are the product of a specific economic system, capitalism (Barnard as cited in Duncum, 2003, p. 19).

As a field, Visual Culture Studies comprise two principal concerns: visual objects and the ways in which we look at them. In this regard "it has similarities with Philosophical Aesthetics since Aesthetics also focuses on object of study and the nature of the aesthetic gaze. The major difference is that Visual Culture Studies consider a much broader range of artifacts and a larger number of ways of looking than does Philosophical Aesthetics" (Duncum, 2003, p. 20). There have been some misunderstandings regarding the content of the term 'visual culture', while some attributed it to conventional media (paint, clay, etc.), others also included popular culture media and technology in the visual culture (Duncum, 2009, p. 70). Visual culture includes and manifests itself as all various forms of visuals, such as photographs, videos, prints, paintings, advertisements, posters, movies, and other visual forms. It also deals with how and under which conditions we look at them. Visual culture is shaped not only by our culture, but also by social conditions, political views, and their complex relationships.

VCAE is an educational approach based on Critical Pedagogy. Students investigate and examine visual phenomena based on Critical Pedagogy; they try to understand them within power relationships, conflicts of interests, individual perspectives, cultural views, political discourses, identity relationships, gender-based power dynamics, social relationships, and inter-communication of all of these (Duncum, 1997; Tavin \& Tervo, 2018).

In the recent years, especially with the widespread use of the Internet, marketing strategies of capitalism have become more detailed, more intense, even adapted scientific new ways, so that they have become more diverse and unpredictable than ever. Even the visuals we perceive as very simple might be a result of a deeper strategy, their influences on our perceptions can be deeper and more sophisticated than we have ever imagined. Under these conditions our childrens' imaginations will be controlled and restricted, their aesthetic experiences and meaning making processes will be disrupted without required pedagogical interventions (Burton as cited in Thompson, 2003, p. 144; Boughton, 2004).

A different perspective suggests that schools are not democratic venues, but rather tools and vehicles for the reproduction of the established system or status quo (Giroux as cited in Heise, 2004, p. 43). In today's world and cultural atmosphere, students view the world through images. The reality which consists of these images is decided by the collective perception. People decide what they like or dislike, what they prioritize or dismiss. In modern psychology, we know that the collective perception may be managed and manipulated sometimes even in a more easy way than individual perception. We need critical pedagogical approaches such as VCAE to educate students who are consciously aware of their individual rights and choices and who develop healthy value judgments (Heise, 2004). Visual cultural analyses based on diverse perspectives and critical discourses will also contribute to democracy in a diverse society. 
VCAE has been based on Cultural Studies, Material Culture Studies and Contemporary Art practices from the beginning (Duncum, 2003, p. 19). While Visual Culture Studies focused on wide-spread sign systems such as TV, Material Culture Studies focused on cultural objects in a more general sense. They both believe in fundamentally re-structuring art education within that context. If we look at the current practices at US schools, teachers adapt individual methods which include both approaches in a more or less eclectic way (Duncum, 2003, p. 19).

Most educational systems in the world today are structured based on standardized educational objectives and standardized tests. Critical thinking skills and creativity are rhetorically mentioned without any meaningful practices or outcomes. Most educational systems and curricula are based on Modernist academic rationalism. In this context, whenever someone talks about visual culture, art is also included. When fine arts and visual culture are mentioned together, it means to imply fine arts and popular culture. This misunderstanding results in a perception and understing that visual culture means only popular culture. If we look at all the articles written about visual culture from the beginning, we can see that visual culture has a broader content, which includes both fine arts and popular culture (Duncum, 2009; Boughton, 2004).

When Visual Culture approach was emerging, whether it was an educational theory was also questioned, because to be defined as a theory it needed to be philosophically structured and its educational applications also needed to be formed based on the theoretical foundations (Duncum, 2009). Nowadays, there are many forms of applications and practices of visual culture approach and it is widely accepted as a theory. We could say that Visual Culture Theory was emerging at the beginning of the 1980s, when Paul Duncum suggested that popular culture needed to be taught not as an introduction to fine arts, but as an independent subject based on social-critical discourse (Duncum, 1982; 1987).

There have been various classroom practices claiming to be visual culture applications. Visual culture applications sometimes may be experienced as student-centered critical inquiries and pedagogical approaches based on Critical Theory discourse; and sometimes can be observed as classroom practices involving analyses and de-construction of popular images reflecting issues of gender, ethnicity, and social class. For the latter, currently there are few or no creative studio practices. Another approach is the conventional art making applications following conceptual de-construction of videos or digital images. However, Duncum (2009) suggested that "skills and insights available through one medium do not necessarily transfer to another; skills and knowledge are medium specific. As one does not study photography to learn how to draw but studies other drawings, so it makes best sense that when critiquing electronic media students respond with the use of electronic media" (p. 71).

\section{Material Culture}

Material Culture Studies is another discipline closely related to Visual Culture Theory which emerged following Visual Culture Studies. While VCAE specifically focuses on visual images and visual communication tools, Material Culture Studies focus on cultural objects, objects used every day and commonly, and all objects which are reflections and tools of culture and daily life. In this regard, food, objects used commonly in a specific culture, objects used in work environment, in cultural and social environments, their functions and meanings in people's and society's lives are the content of study in Material Culture Studies. These objects may be interpreted within their sociological roles and functioning, political power relationships, and other relationships within culture and environment. "Material culture is the segment of humankind's biosocial environment that has been purposefully shaped by people according to culturally dictated plans" (Schlereth as cited in Duncum, 2003, p. 21). Material Culture Studies use objects to understand human behavior, mind and actions. The material is what we can see, touch and smell, 
but which is not human or animal. The culture is the set of common human practices that surround material objects, the ways of using material, of sharing it, of talking about it, of naming it and of making it (Dant as cited in Duncum, 2003, p. 21).

Material Culture is multi-disciplinary in its nature. Emotions of people who created these objects, their sensitivities, belief systems, folkloric qualities of the objects, ethnographic contents and environments, sociological context in which it is used or situated, geographical location and cultural relationships may all be taken into consideration. The "things' within this complexity are in the scope of Material Culture Studies. Those things sometimes may accommodate mythological or metaphoric meanings. If we think about cultures as sophisticated sign systems, those "things' may represent a language or an expressional tool of a certain culture.

In fact, if we observe our lives, we can see that we spend more time with things than with people. We are constantly together with things; they are parts of our lives. Almost all of us own or collect things from our past lives in a cabinet or in a drawer, as well as experiences, sometimes we have things with deep meanings and memories we may even have difficulty to explain. Those things are not just objects for us, but a part of our lives, connection with a past experience or with a memory, a part of our personal identity. Sometimes, this meaning elaboration is related to its shape and form, sometimes it may be explained as a form of culture we belong to, and sometimes it may be more personal, individual and may be difficult to explain and more specific. "Sometimes ordinary objects 'convey and condense' ideas about the world and our place in it so that the link between artifacts and identity is an intrinsic and profound feature of social experience" (Myers as cited in Duncum, 2003, p. 21).

Western society today can also be described as a consumer society, and culture can be defined as consumerism. In this respect, ideas, values and beliefs are exchanged through consumer materials among people as being sold or being bought. These materials are also introduced into our cultural lives through social communication process. The objects we choose to buy and even the objects we refuse to buy permit us to position ourselves among others, help us to create our own meaning systems, and even our own identity within this consumer culture. Even if one is against this consumer system, $\mathrm{s} / \mathrm{he}$ is also inevitably a part of this process and the culture. All the objects, materials and things within this process are also within the scope of Material Culture. This wide scope and spectrum of objects and materials make this field an alluring field of study and an educational process. Every thing in this respect could be used to understand and make meaning. On the other hand, the wide scope of Material Culture creates doubts about its relationship to art education and creates ambiguity about applications and practices.

While material culture studies have interest in the material which is used to make the object, VCAE has interest in the 'viewing' and the conditions in which viewers look at the image. VCAE always views the society within conflicts of inequalities and injustice within power and dominance relationships. The meaning making process within this course is described as representations of hegemony, power and domination of groups. Material Culture, on the other hand, focuses more on social and cultural functioning of objects, and suggests that even if they seem in conflict at times, all elements of society work together in harmony (Duncum, 2003, p. 22). Duncum also makes a comparison between the two fields as follows:

\section{Visual Culture Studies}

- Focus on two-dimensional images.

- Are overtly symbolic.

- Are deliberately communicative.

- Involve conditions of seeing.

- Deal with conflicting views of society. 


\section{Material Culture Studies}

- Are focused on three-dimensional artifacts.

- Are utilitarian

- Are inadvertently communicative.

- Deal with materiality of artifacts.

- Deal with the functional view of society.

(Duncum, 2003, p. 22)

Material Culture Studies explore cultural objects, artifacts which are the results of a long history of cultural heritage. These objects and artifacts are examined and investigated within social, historical and cultural contexts. On the other hand, VCAE provides new perspectives and deeper understandings of class conflicts and power dynamics within the society. Furthermore, especially objects and images of popular culture may be the tools of marketing strategies of capitalism and they are still parts of power struggles. It is obvious that we have to teach our students all these sophisticated relationships and structures through educational interventions.

\section{Discussions Regarding Modernism}

Modernism has been criticized profoundly since the 1970s. It was seen as part of a status quo, a symbol of apolitical stance, and almost like a disease to be kept at a distance (Efland, 2005). Especially, VCAE opponents largely criticized long historical influences of Modernism on science, art and education. Modernism is a part of the West's philosophical evolution. The Period of Enlightenment and then French Revolution have deep influences on the Modernist idea, and Enlightenment philosophy is mostly rooted to Aristotelian Rationalism. It is interesting that dicussions and criticisms regarding Modernism go back to Platonic Idealism (Idealist Realism) and Aristotelian Rationalism. If we remember the historical conflicts in the European Christendom, then Lutheran Reformation against Roman Catholicism, it is no surprise that the West finally found refuge in rationalism and later in Modernism. Enlightenment ideas provided a refuge and were a promising change in almost all areas of life including science, art, religion and politics. Having completed its long historical mission based on progressiveness, Modernism started to be increasingly criticized after the 1960s. Modernism and tradition conflict goes far back, however, the strongest arguments against modernism were put forward by Frankfurt School, Marxist ideology and Postmodernism.

Foucault traced the 'attitude of modernity' to Immanuel Kant's short text on the Enlightenment written in 1784. Foucault explains that Kant was not seeking to understand the present on the basis of a totality or of a future achievement. He was looking for a difference: What difference does today introduce with respect to yesterday? (Foucault as cited in Tavin \& Tervo, 2018, p.285)

The fine arts tradition and especially the academic art have deep roots going back to Ancient Greece. Modernist idea was rather revolutionist in its nature and found these traditions conservative and viewed them as constraints against progress and change. The wind of modernity and change resulted in the emergence of many art movements in Europe. The attempt against strong and old fine arts tradition prompted questioning the concept of 'art' itself. The resulting confusion created many art movements, many of which tried to define art differently with radical manifestos. It is thought-provoking that having been criticized as being elitist and causing a division of the so-called high art and low art, Modernism was against fine arts and academic 
art, which are seen as high art forms. Interestingly, within the Postmodernism discussions Modernism has come to a position that it is now safeguarding the tradition. Scientific method based on empiricism and rationalism has greatly contributed to our philosophy of thought and progress for over 200 years. Nonetheless, Modernist idea declared rationalism as the new sacred and turned it into a new dogma. Once saluting the change and progress, Modernism abandoned its own raison d'être, rationalism turned into the new church especially in the academia. Most art education applications and practices

appear to be based on the idea that there is something qualitatively special about the fine arts. The fine arts are said to put us in contact with the most original, creative, subtle, intense, humane, honest, and inspiring aspects of ourselves and society. By contrast, the images through which the great majority of people create meaning are seen as pandering to the worst in society: to be conformist, violent, sentimental, and manufactured only with dollar signs in mind. (Gans as cited in Duncum, 1997, p. 70)

Duncum (1997) disagrees with such a distinction in terms of value (p. 71). Such a distinction results in a separation of high art - low art; and the opposing view can be seen as a stance against hundreds of years of status quo. Feminist, Marxist and Postmodernist views are against such a distinction and they see this distinction as a product of Modernist idea. On the other hand, VCAE and similar approaches were blamed to be Postmodernist and Neo-Marxist views. Today, "while so called high art forms are segregated from public and located in the museums and galleries, most people express themselves through mass media and popular culture images, structure their relationships and even their identities through mass media and pop-culture images" (Duncum, 1997, p. 70). On the other hand, it seems conflicting that Duncum also thinks that popular culture images are the tools of power structures and hegemony in a capitalist society. Popular culture images and media may also be used as a tool to manipulate and even structure the views, perspectives, beliefs and even decisions of individuals or even masses. Duncum does not advocate exclusion of fine arts from the curriculum. He acknowledges that fine arts have significance in our cultural heritage and have a function in our culture; however, popular culture also has an increasingly new place in our lives and culture, therefore, it should also be part of the curriculum (Duncum, 1997, pp. 71-72).

Modernist design was claimed to be a reflection of socialist ideology, because, when it first appeared, Modernist design preferred functionality and easiness of industrial production to cultural style characteristics. It adapted a design and architecture philosophy that purposefully omitted cultural identity from style. Similarly, at the beginning modern painting was seen as a conspiracy of communism (Efland, 2005, p. 37). Astonishingly, today, VCAE, which is against Modernist ideas, is claimed to have a hidden Marxist agenda. Furthermore, products of functional architecture, steel and glass structures of skyscrapers are seen as the icons of capitalism and corporate dominance (Efland, 2005, p. 37).

Disconnection of disciplines and branches of knowledge is seen as one of the flaws of Modernism. Modernist idea does not adapt a holistic understanding of knowledge, but creates an autonomous divide. The autonomous divide of disciplines also creates new groups of experts and specialists in areas of division (Efland, 2005). Even though this division of knowledge and branches was seen as a good idea at the beginning, over time it caused unexpected problems, especially in education. Knowledge is holistic in its nature and divisions between disciplines cause difficulties in comprehensive understanding of knowledge. "Looked at from this perspective, the attempt to characterize the arts as free standing disciplines culminated in the movement known as Discipline-Based Art Education (DBAE). The visual arts were set apart from the cultural influences that gave rise to them, and this was a grave error" (Efland, 2005, p. 37). As an opponent of VCAE, and also critical of Modernist approach, DBAE has come to a position where it represents fine arts and academic art traditions against which Modernism once fought. It may seem contradictory; however, the perspectives and understanding may have changed based on changing power dynamics and conflicts of interests over time. 


\section{Applications and Practices of Visual Culture Art Education (VCAE)}

With the emergence of Visual Culture Theory, which brought new perspectives to visual images beyond formalism, there needed to be concrete examples and principles to be applied in the classroom. Duncum (2010) suggested seven principles to be used while examining visual images. These are: power, ideology, representation, seduction, gaze, intertextuality, and multimodality.

1. Power is the key principle, because most of the other principles intersect with the issues of power. Who exercises power through imagery? What kind of power? How, when and why is it exercised? Power is central to a consideration of imagery because all images involve an assertion of ideas, values and beliefs that serve the interests of those for whom they are made - political, social, and economic - and audiences, in their turn, exercise the power of interpretation (Duncum, 2010, p. 6).

2. Ideology: Hidden or obvious, images are the representations of ideological struggle. Ideology may be worldviews, ideas, ideals, beliefs, and values. It is a systematic way of thinking, a frame, a style of thought, an interpretive scheme employed by people to make the world intelligible to themselves (Duncum, 2010, p. 7). Visual images may reveal ideologies that reveal the hopes, fears, expectations, certainties, uncertainties, and ambiguities of our lives (Duncum, 2010, p. 7). Ideologies may also clash and images may be representations of these power clashes. In a consumer society, lack of ideology within images may also be the ideology in itself.

3. Representation is closely aligned with ideology because it refers to how ideology is presented in visual form. It involves what images represent, how they represent it, and what they fail to represent, what is seen and what is obvious, what is privileged, supported, favored and what is condemned, criticized or marginalized, what rhetorical tools are used to influence or manipulate our understanding of what is represented. Representations are the purposefully selected elements and frames to direct a viewer's perception toward a certain way. The people represented in media are also subject to stereotyping: for example, of women, men, ethnicities, and sexual orientation (Duncum, 2010, p. 8).

4. Seduction: Visual images have a seductive power of their own. Ideologies often come hidden in seductive forms. Images may seduce viewer in many ways. "When images offer arguments that reflect back our own views, our own ideological positions, they offer the pleasure of confirmation. We all come to images with a state of frame and stereotypes in mind, to see them represented is to experience the pleasure of feeling justified in our views" (Duncum, 2010, p. 8). Images may offer the fulfillment of deep-seated, even unconscious, desires, including pleasures socially viewed as taboos (Zizek cited in Duncum, 2010, p. 8). Images are also seductive because they are sensory. Sometimes sensory qualities or ideas / ideology behind the representation may attract the viewer. "Sensory lures are important because they act to wrap ideologies in pleasurable forms that make rejecting ideologies more difficult" (Duncum, 2010, p. 8).

5. Gaze: The gaze is closely related to philosophical aesthetics and concerns how we look at images and the circumstances under which we look at them. It refers to our predisposition to see things in certain ways, what we bring to images, and the relationships we form with them. In art museums we have a better chance to isolate and disconnect the images from environmental effects and gaze in a disinterested way as Kant suggested. However, outside the museum, in everyday life, a disinterested gaze will be more difficult if not impossible. We are all constantly surrounded by images, and we gaze in numerous ways. Our perception, within an unlimited number of stimuli, our world views, identities, beliefs and ideology all have an influence on our gaze. Therefore, "our relationship to images can be predetermined as sexist, ageist, or racist, but also as sympathetic, respectful, and loving" (Duncum, 2010, p. 8).

6. Intertextuality: All images may relate to other cultural expressions such as books, poems, music, and other images. Images may have connections to other forms of expressions in such ways as drawing from other images, reproducing ideologies, associating texts, copying other images, caricaturizing them, explaining and supporting them (Duncum, 2010, p. 9). VCAE is a 
learning process and a very useful tool of meaning-making in which we see connections. Everything is connected to other things in some way, and we have to remember that sometimes creators of visual images purposefully make these connections.

7. Multimodality: Multimodality refers to the fact that there are no purely isolated visual images; images never appear without words, music, or other sounds. Even in art galleries images appear with labels, and their assumed significance is deeply grounded in art history texts and columns of written critique. The images may anchor to certain music, sounds, texts, words, slogans, sound effects and speech. The multimodal nature of imagery is yet another reason for considering images in terms of their context (Duncum, 2010, p. 10).

\section{Critiques of Visual Culture Art Education}

VCAE has gained popularity increasingly over the last two decades. It emerged as an educational theory, so criticisms were also mostly based on educational concerns. The major of these concerns was assessment. VCAE is fundamentally based on Critical Theory and it is highly sophisticated as an educational approach. Sociologically structured issues are highly intricate in their nature and these issues require historical, sociological, political, and cultural understanding in a contextual manner. These multifaceted phenomena will require advanced teaching skills, and it may not be possible to teach some of these in a limited class time and to a certain level. Similarly, these elaborate phenomena will not be very easy to teach and evaluate in a standardized curriculum (Boughton, 2004). Even though it will be more difficult compared to standardized tests, Boughton (2004) suggested digital portfolios as an assessment tool for VCAE (p. 268).

Another major criticism of VCAE is that it defines art and all visual culture as part of societal power struggles and hegemony. From Critical Theory perspective, everything happening around us, including visual phenomena, could be explained based on unequal power and dominance relationships in the society. Because of this critical view and perspective, VCAE is deemed to have a Neo-Marxist, radical Left agenda (Smith, 2005, p. 287; Pariser, 2019). This highly political view and understanding of VCAE is being criticized. Moreover, Efland (2005) and Smith (2005) criticized removing art and visual products from aesthetical contexts and treating them as only symbols of power struggles. They suggested that philosophical aesthetics and art tradition have a value and belong to a tradition going back to thousands of years; new approaches may be built upon these traditions (Smith, 2005, p. 287).

Similarly, according to Efland (2005), rejection of thousands of years of tradition, which was based on aesthetics and humanistic values, and rejection of artistic values is a big mistake. If one treats art including historical heritage of fine arts only as power domination tools of upper social classes, and if $s /$ he does that based on some egalitarian motive (p. 240), this means s/he misses thousands of years of values and heritage. Similarly, Pariser (2019) rejects the idea that whole visual culture represents and is shaped by social dynamics and should be evaluated based on social-cultural relativitity perspective (pp. 72-73).

From evolutionary perspective, there are very old, ancient evolutionary codes of survival behind our aesthetic reactions, artistic creation processes, and the art forms we created. Social-Constructivist approaches such as John Locke's claim that human mind is created as a blank slate (tabula rasa) and later shaped by environmental stimuli from scratch are not commonly accepted theories. We have empirical evidence today that human mind and psychology are born with cultural and psychological inheritance from our ancestors. Our views of visual objects are not shaped based only on social and cultural variables and dynamics. Our sense of taste and aesthetical choices are also rooted in our evolutionary genetic inheritance (Dutton, 2009; Dutton, 2013, p. 694).

Pariser (2019) harshly criticized Kallio and Tavin for having an approach based on provocation pedagogy. He especially criticized Tavin for defending provocative applications during his professional carrier as a so-called 'justice warrior' ( $p$. 70). If we 
look at all the critiques of VCAE such as being a Neo-Marxist and Radical Left approach, such provocation-based approaches have their ground in Marxist ideology. Marxism as an ideology is principally based on viewing and understanding the society and phenomena in terms of social class conflicts, alienation and power relationships. Phenomena are analyzed based on hegemony, inequality, and class conflict; the individual is purposefully alienated and provoked if needed, by means of doing this societal structure is disintegrated and then destroyed effectively (Stanford Encyclopedia of Philosophy, 2020). "We always expect épater la bourgeoisie (shocking to the middle class and disturbing) applications in art; however, if we are talking about art education, it has to be discussed based on whole pedagogical methods and practices" (Pariser, 2019, p. 70). It might also be helpful to remember another claim that a popular pedagogical method, critical thinking, is being used by VCAE as a blanket term to hide social and ideological critique (Pariser, 2019, p. 72).

According to Smith, VCAE is a threat to art education in terms of its structure and content. If it continues in the same way, art education, which has a long historical tradition, will be badly damaged. Enculturation is a process of learning, in which an individual learns the surrounding culture and the traditional content of universal culture, and assimilates these values (MerriamWebster, 2021). According to Smith, fine arts, which are also called 'elite arts', have historical roots; and they have a great potential for enculturation process and lifelong learning. This potential is much bigger compared to visual cultural forms that are meaningless, daily, monotonous and mechanic (Smith cited in Tavin \& Tervo, 2018, p. 287). Similarly, Beardsley suggested focusing more on formal aesthetical characteristics of art in art education than on cultural criticism (Beardsley cited in Smith, 2005, p. 287).

The criticisms of VCAE at the beginning was based on modernist and postmodernist views. Modernist view suggested that approaches and definitions regarding art and its meaning were clear and concise; and did not create any questions or concerns. Contrastingly, approaches such as VCAE bring generalized, conflicting, confusing definitions or explanations to art and they are clearly irrelevant. The Modernist view supports a Kantian approach and distinction such as high culture - low culture. These criticisms viewed VCAE as Postmodernist confusions going against mankind's evolutionary nature and progress (Pariser, 2019).

There have been serious concerns regarding ideological roots of VCAE. Slovenian Prime Minister Janez Jasa (2020) claimed that Marxists faced a strong opposition following violent student movements of the 1960s and 1970s, so they went underground. Postmodernism is a cover up for these Marxists, they just re-appeared with a new badge. Jasa also pointed that the emerging violence based on identity politics in Europe is not different from Communist Manifesto written over 200 years ago. He further explained that "to build a new world order Marxists have to disintegrate nations, family structure, private property, private schools and religions, this is what they call Cultural Marxism" (Jasa, 2020). According to Jasa's explanations, World War I did not bring about the realization of the Marxist dreams of the global working class joining forces and launching the revolution of the proletariat. Therefore, leftist sociologists gradually stripped Marxism of its economic component and replaced it with freshly infused sociology and psychology theories. Thus Critical Theory, also known as Cultural Marxism, was created. According to Max Horkheimer (as cited in Jasa, 2020), the traditional concept of family, sexual norms, and morality must be deconstructed, Christian foundations, conservatism and patriotism must all be abolished. He was not alone, the intellectual name behind the 1960s' student movements in France, Herbert Marcuse; created the concept 'The Great Refusal', meaning to destroy all traditional values (Jasa, 2020).

As Western communists do not believe that they would succeed in a violent attempt to overthrow traditional Western societies, they advocate for subverting them through the patient application of ideological indoctrination and the undermining of social institutions. They hope to achieve this through the occupation of universities, dominating cultural life, the creation of political networks based on identity politics wrapped in the guise of social justice. Some tools of these Neo-Marxists (Critical theorists, Cultural Marxists, postmodernists) used to destroy social structure and institutions were: multiculturalism, progressivism, 
radical feminism, gender ideologies, political correctness, identity politics, LGBTQ politics, struggle against exclusion, Open Society (Société Ouverte) movement, environmentalism and ecological activism (Jasa, 2020; Peterson, 2018). With the influential use of Political Correctness, the identity politics widely and increasingly finds publics support in the recent years.

The unsuccessful attempts based on bourgeoisie/proletariat conflicts yielded a new terminology such as oppressor/oppressed. Provocation through identity politics on the basis of oppressor/oppressed dichotomy was the new game, the same Marxist game in a new guise, Postmodernism (Peterson, 2018). One of the central claims of Postmodernism is that "there is an infinite number of ways to interpret any finite set of phenomena." It is also not acceptable to favor one of those numerous interpretations to another. Therefore, the suggestion to understand and analyze the social construct based on oppressor/oppressed dynamics actually contradicts Postmodernists' own claim (Peterson, 2018). On the other hand, VCAE approaches may be necessary in a democratic society to build informed citizens who think critically (Heise, 2004). However, teachers also have concerns and confusions regarding classroom applications and studio practices (Heise, 2004, p. 42). Nevertheless, art teachers have to be wellinformed about social and cultural phenomena, since VCAE needs them to view and analyze visuals based on sociological, political, historical, cultural, geographical, and psychological contexts and perspectives.

\section{Methodology}

\subsection{Objective of the Study}

Visual Culture Theory is a more recent art education theory compared to well known DBAE, the Discipline-Based Art Education. The objective of this study was to investigate whether or not art teachers are informed about VCAE and to what extent they are informed about the VCAE content. The study also aimed to explore art teacher preferences and tendencies regarding the VCAE content and principles; what issues they anticipate to encounter during the application and practices of VCAE. Participant responses to the survery questionnaire were analyzed in relation to participant demographics such as years of experience in teaching and educational attainment.

\subsection{Research Questions}

1. How much and to what extent are art teachers informed about Visual Culture Theory, its principles and content?

2. What do art teachers think about the applicability of foundational principles of Visual Culture Theory?

3. According to art teachers, what basic principles of the Visual Culture Theory may be problematic in terms of their applications and practices?

\subsection{Research Design}

Teacher opinions about the VCAE content were collected through an online survey. The questionnaire was structured as an exploratory descriptive survey. Teacher opinions about Visual Culture Theory and its content, their preferences and tendencies regarding the content and principles of VCAE were explored through a 10-item survey questionnaire. "Descriptive survey is a suggested and preferred method of investigation to explore participants' knowledge, opinions, preferences and tendencies about a particular topic or issue" (Fraenkel \& Wallen, 2000, p. 431). "Descriptive surveys help to quantitatively describe a population's attitudes, tendencies, and opinions based on study of a selected sample group, therefore inferences about the population may be possible" (Creswell, 2014, p. 155). 


\subsection{Sampling}

The study was conducted on a sample group of art teachers currently working at public or private schools, those who previously worked as art teachers, and recently graduated art teachers without working experience. Purposive, convenient, random sampling method was employed to represent a population of art teachers from various backgrounds, with various experience levels, with educational experience from various universities, working in diverse geographical regions and towns in Turkey. Convenient sampling helped to reach out to art teachers through online social and professional networks and associations of art teachers. The online social networking tools Facebook, Twitter, and Instagram were used to reach out to the participants. Some participants were also informed and asked for their voluntary involvement through email listserves.

As part of institutional requirements and ethical concerns, the application of the data collection instrument and human subjects was approved by the institutional ethics committee before collecting any information. Participants were informed about the study and asked for their consent to be involved in the study. A total number of 71 art teachers completed the online survey on a voluntary basis. The sample group gives an idea of teacher opinions and perspectives regarding the VCAE and its content. The sample size, diversity and dimensions of the collected information may represent the population effectively. The information collected was grouped, classified and analyzed based on relevant demographics when needed. Relevant demographics included the years of experience, type of school graduated (i.e., School of Education, School of Fine Arts), level of education completed, whether or not the participant obtained teaching certification after undergraduate degree.

Table 1.

$\mp$ Participant profile: years of teaching experience

\begin{tabular}{|c|c|c|c|c|c|c|c|c|}
\hline $\begin{array}{l}\text { Service } \\
\text { Years }\end{array}$ & $\begin{array}{l}\text { Number of } \\
\text { participants (f) }\end{array}$ & $\begin{array}{l}\text { Ratio } \\
(\%)\end{array}$ & $\begin{array}{l}\text { Service } \\
\text { Years }\end{array}$ & $\begin{array}{l}\text { Number } \\
\text { (f) }\end{array}$ & $\begin{array}{l}\text { Ratio } \\
(\%)\end{array}$ & $\begin{array}{l}\text { Service } \\
\text { Years }\end{array}$ & Number (f) & $\begin{array}{l}\text { Ratio } \\
(\%)\end{array}$ \\
\hline 0 & $\bullet \bullet \bullet \bullet \bullet \bullet$ & 8.45 & 10 & $\bullet$ & 1.41 & 20 & $\bullet \bullet$ & 2.82 \\
\hline 1 & $\bullet \bullet \bullet \bullet \bullet \bullet \bullet \bullet \bullet \bullet$ & 14.08 & 11 & $\bullet$ & 1.41 & 21 & $\bullet$ & 1.41 \\
\hline 2 & $\bullet \bullet$ & 2.82 & 12 & $\bullet \bullet$ & 2.82 & 22 & $\bullet \bullet \bullet \bullet$ & 5.63 \\
\hline 3 & $\bullet \bullet \bullet \bullet \bullet$ & 7.04 & 13 & $\bullet \bullet \bullet$ & 4.23 & 23 & $\bullet \bullet$ & 2.82 \\
\hline 4 & $\bullet \bullet \bullet$ & 4.23 & 14 & $\bullet$ & 1.41 & 24 & $\bullet \bullet \bullet \bullet \bullet \bullet$ & 8.45 \\
\hline 5 & $\bullet \bullet \bullet \bullet \bullet \bullet$ & 8.45 & 15 & - & - & 25 & $\bullet \bullet$ & 2.82 \\
\hline 6 & $\bullet \bullet \bullet$ & 4.23 & 16 & - & - & $\ldots$ & $\ldots$ & $\ldots$ \\
\hline 7 & $\bullet \bullet$ & 2.82 & 17 & - & - & $\ldots$ & $\ldots$ & $\ldots$ \\
\hline 8 & $\bullet$ & 2.82 & 18 & $\bullet$ & 1.41 & $\ldots$ & $\ldots$ & $\ldots$ \\
\hline \multirow[t]{2}{*}{9} & $\bullet \bullet$ & 4.23 & 19 & $\diamond \bullet$ & 2.82 & 39 & $\bullet$ & 1.41 \\
\hline & & & & & & & $\mathrm{N}: 71$ & 100 \\
\hline
\end{tabular}


Table 2.

Participant profile: type of school graduated

\begin{tabular}{lcc}
\hline Type of school & Number of participants $(f)$ & Ratio (\%) \\
\hline School of Education & 68 & 95.8 \\
\hline School of Fine Arts* & 3 & 4.2 \\
\hline
\end{tabular}

*Participants who graduated from School of Fine Arts and also obtained teaching certification.

Table 3.

Participant profile: education level attained

\begin{tabular}{lcc}
\hline Education level & Number of Participants ( $f$ ) & Ratio (\%) \\
\hline Undergraduate & 58 & 81.7 \\
\hline Master's student & 5 & 8.6 \\
\hline Master's degree & 8 & 13.7 \\
\hline Doctoral degree/Art qualification & - & - \\
\hline
\end{tabular}

\subsection{Instrumentation}

The survey questionnaire was developed based on Visual Culture Theory content, foundations and principles as explained in the reviewed literature. The questionnaire included 10 questions along with demography questions. Online survey was the appropriate choice of instrument considering the convenience to reach out to the participants, ease of information collection and time management. An online survey design tool, Google Forms, was used; it was conveniently available to reach out to art teachers who work in various geographical regions and locations. The questionnaire included only VCAE content-related questions, participant responses remained anonymous and no personal information was collected.

The term visual culture is a conventional term used in our daily lives to describe all visual cultural elements we are exposed to everyday. On the other hand, VCAE is an art education theory which differs significantly in its meaning and involves specifically Critical Theory-based content and applications, as explained in the previous chapters. However, it causes some confusion when someone talks about 'visual culture in art education' because of the conventional meaning of the term used everyday. Therefore, the terms 'Visual Culture Theory' and 'visual culture' were not used in the questionnaire to prevent possible misunderstandings. The questionnaire included questions about theoretical foundations and principles of VCAE, and teacher opinions of their application and practices in the educational settings. It also included questions about possible problems and concerns regarding the application of VCAE in Turkey.

\subsection{Variables}

The VCAE theory-related questions included the following content: societal power structures, dynamics and relationships in relation to VCAE content; gender, ethnicity and identity politics content within power relationships in the society, as well as religion and belief-related VCAE content in art education. The questions were investigated in relation to the following variables: art teachers' service years, educational attainment, their knowledge of VCAE content, teachers' opinions of VCAE applications and practices, the problems and difficulties they anticipate regarding the application of VCAE at schools.

\subsection{Validity and Reliability}

The survey questionnaire was designed based on the principles and philosophy declared by the scholars who were developing the VCAE over two decades. Personalized inferences were not used while designing the survey questionnaire. Expert opinions of 
three art education specialists were also obtained to structure the questionnaire concisely without bias. Each question was structured to obtain teacher opinions about fundamental principles of VCAE. Sometimes, the same principles were included in various questions as structured differently to confirm that the expected responses are not coincidental, not circumstantial or misunderstood, but they are coherent and intentional. This approach was used for response validation to prevent multiple inferences of meaning from a certain answer and to establish internal validity measures effectively. Response validations between items were confirmed through clustering the percentage ratios of responses. Clustering the ratios of responses provided construct validity - that the questions measured the corresponding indices.

\subsection{Results}

In this study, teacher opinions of VCAE were investigated through responses to a survey questionnaire in relation to the research questions. Participant responses were analyzed in relation to corresponding demographics, analyses were reported descriptively within measures of frequencies, percentages and distributions of responses. The first question in the survey was related to a fundamental principle of VCAE.

Table 4.

Question 1: Do you think that societal power relationships and structural hierarchies should be brought into the classroom and discussed?

\begin{tabular}{lcc}
\hline Responses: & $\mathbf{f}$ & \% \\
\hline No, I don't think so & 36 & 50.7 \\
\hline Yes, I think so & 23 & 32.4 \\
\hline Not sure & 12 & 16.9 \\
\hline & $\mathrm{N}: 71$ & $100 \%$ \\
\hline
\end{tabular}

Question 1: Do you think that societal power relationships and structural hierarchies should be brought into the classroom and discussed? Based on participant responses to question\#1, 50.7\% (36) of teachers responded 'No, I don't think so'; 16.9\% (12) 'Not sure', and 32.4\% (23) 'Yes, I think that societal power relationships and structural hierarchies should be brought into the classroom and discussed.' When asked without making any ideological connections, some participants reacted: "What is it with art education?" (meaning 'is it irrelevant to art education?'). Interestingly, the term 'Visual Culture Theory' was not mentioned anywhere either in the questionnaire, or in the consent form. In this case, it might mean a few things: first of all, a teacher who is aware of VCAE would not have responded with such a reaction, it was just another sign that VCAE was such an 'unknown' educational theory. Furthermore, it might mean that art education became so conventional in its content and curriculum over time that typically some art history and studio content are what it typically includes. From this conventional perspective, social and political issues were not within the scope of art education or because of some unknown concerns teachers believed that there had to be a distance between art education and social, political issues. Responses to question \#1 also showed a strong (50.7\%) disagreement, and these results might be connected with the same perspective as already mentioned.

Another question based on VCAE principles was question \#2: "Do you think that discussions of societal issues of gender, identity and power relationships bring politics into the art classroom?" Table 2 below shows the responses to this question. 
Table 5.

Question 2: Do you think that discussions of societal issues of gender, identity and power relationships bring politics into the art classroom?

\begin{tabular}{|c|c|c|}
\hline Responses & f & $\%$ \\
\hline No (Total) & 19 & 26.76 \\
\hline Master's student or Master's degree & (6) & \\
\hline Yes (Total) & 39 & 54.9 \\
\hline Master's student or Master's degree & (4) & \\
\hline Master's student or Master's degree & $(2)$ & \\
\hline Undergraduate degree & $(10)$ & \\
\hline \multirow[t]{2}{*}{ No response } & 1 & 1.41 \\
\hline & $\mathrm{N}: 71$ & $100 \%$ \\
\hline
\end{tabular}

Table 5 showed that $54.9 \%$ (39) participants responded to this question with "Yes, discussions of societal issues of gender, identity and power relationships bring politics into the art classroom". It should be mentioned that in Turkey, people always talk about politics in daily life; politics has an immense place in their lives; they even take politics into consideration when choosing their friends; furthermore, political divide and discussions cause a strong tension between people and groups. Therefore, it is hard to find peace and calmness when there is political talk and it often ends with arguments. The central authority, National Ministry of Education, restricts political talks and content in the classroom. The 2020 presidential elections in the US caused a new and unexpected divide in the American society. This new divide is unusual in the society, since people used to respect individual choices and preferences. Therefore, an educational theory such as Visual Culture Theory was able to bring political discussions into art classroom without further concerns. However, in politically polarized societies, we expect a deeper concern when bringing politics into the classroom. Henceforth, after the recent US election accompanied by great political frictions, talking about politics in the classroom may cause concerns and sensitivities.

The responses within this perspective showed that teachers have the same sensitivities or they simply feel that they have to follow regulations accordingly. On the other hand, there is a potentially politically-motivated group of 23 teachers (32.4 \%) who might think that they should go out of regulations and curriculum restrictions, that they should go beyond central ideology of the government and bring gender, ethnicity, politics and power relationships into the classroom (question \#1, Table 4). In this sense, we could say that teachers' perspectives about bringing these politically oriented matters into the classroom are also influenced by their political orientations and worldviews. As we all know, educational policies are typically structured based on ruling ideologies, too.

Question \#2 was: "Do you think that discussions of societal issues of gender, identity and power relationships bring politics into the art classroom?" As seen in Table 5 above; 6 participants (out of 19) who responded with 'No' to this question have either a Master's degree or they are Master's students. Master's students, in particular, become familiar with VCAE during their graduate studies, therefore, it was expected that the participants with an educational attainment further than undergraduate degrees are informed of VCAE and possibly have a positive view of VCAE, since this theory has been popular over the last two decades. 
Table 6 .

Question 3: Do you think that politics should be discussed in the art classroom?

\begin{tabular}{|c|c|c|c|}
\hline \multicolumn{2}{|l|}{ Responses } & f & $\%$ \\
\hline \multirow[t]{3}{*}{ No (Total) } & & 57 & 80.2 \\
\hline & Master's student or Master's degree & $(11)$ & \\
\hline & Undergraduate degree & $(46)$ & \\
\hline \multicolumn{2}{|l|}{ Yes (Total) } & 6 & 8.5 \\
\hline & Master's student or Master's degree. & (1) & \\
\hline & Undergraduate degree & (5) & \\
\hline \multirow[t]{4}{*}{ Not sure } & & 8 & 11.3 \\
\hline & Master's degree & (1) & \\
\hline & Undergraduate degree & (7) & \\
\hline & & $\mathrm{N}: 71$ & $100 \%$ \\
\hline
\end{tabular}

Table 6 shows responses to question \#3: "Do you think that politics should be discussed in the art classroom?" 80.2\% (57) of the participants responded "No". There may be various reasons for such a high percentage of responses 'No' to this question. Political divide and tension are very common in Turkish society, as previously explained. It might be that the teachers were against bringing this tension and divide into educational environment. The participants were not asked 'why'; following this question, therefore, it is difficult to explain the exact reasons for their responses. Etiquette may show a broad diversity in various cultures. The political divide and tension between major political groups and their voters cause the loss of relative peace; thus, many people developed a conflict avoidance strategy as not talking about politics if possible. As in this conflict avoidance strategy, teachers may prefer not to bring political matters into the classroom.

Table 7.

Question 4: Do you think societal power relationships, gender and identity issues should be discussed in the art classroom by means of visuals and objects?

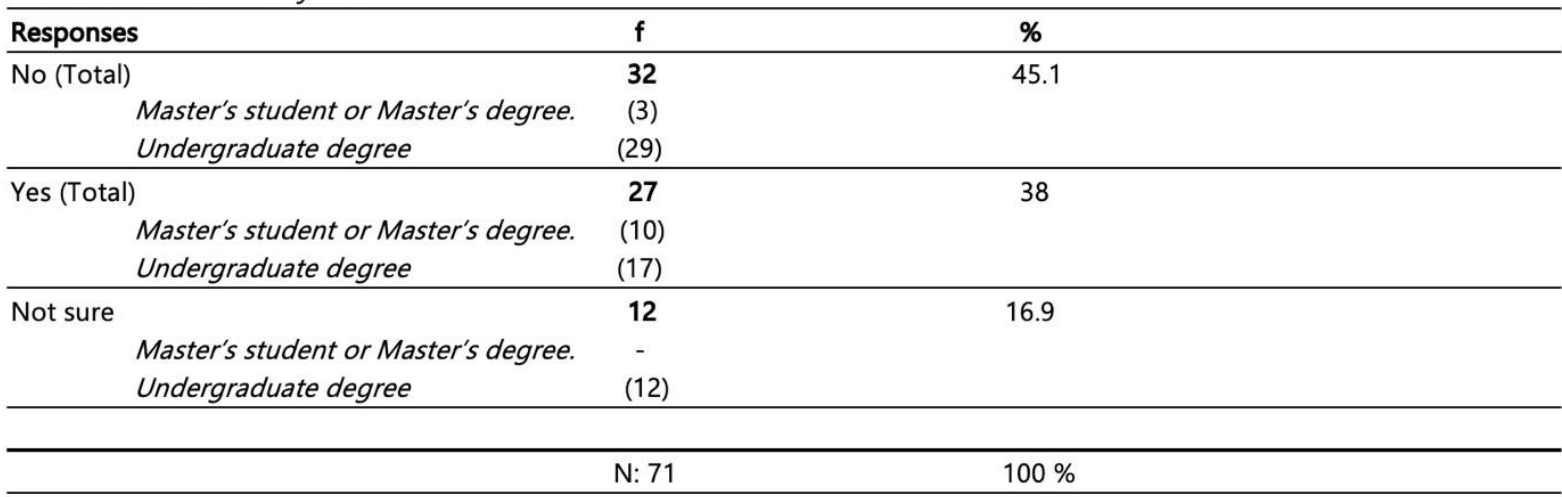

Responses to Question 4 are shown in Table 7. Participants were asked whether they think that societal power relationships, gender and identity issues should be discussed in the art classroom by means of visuals and objects. $45.1 \%$ (32) of the participants think that the issues in question should not be discussed in the art classroom. On the other hand, 38\% (27) of the participants think that they should be discussed in the art classroom; and 16.9\% (12) of the participants were not sure. The responses to the previous question showed that $80 \%$ of the participants thought that politics should not be discussed in the art classroom. However, when the term 'politics' was not used, the participants were comparably more agreeable and thought that societal power relationships, gender and identity issues should be discussed in the art classroom (38\% or 27 participants). When we look at the participants' educational attainment, out of 13 participants who are either graduate students or have a Master's degree, 10 participants agreed that societal power relationships, gender and identity issues should be discussed in the art classroom. While teachers with an undergraduate degree are not usually informed about VCAE, teachers with graduate education are informed and 
more likely tend to think positively about VCAE. The power relationships, gender identity issues, and gender-related power relationships are directly related to politics, but the participants responded differently, as if these issues were not politics. This also may explain why and how Cultural Marxists use these gender identity issues as a social activism movement. We could bring various explanations for these responses. For instance, violence against women is a major social problem in Turkey, and the issue is on the news almost every day. Teachers may have reacted with sensitivity and thought that these issues should be brought into the classroom as an educational responsibility. As unique to Turkey, political conflicts arise mostly based on belief, Islamic conservatism and Laïcité (secularism) issues. Therefore, issues such as gender and identity are less likely to be considered as political and controversial compared to religion and secularism politics. Open-ended questions may be needed to clarify the reasons for the participants' responses to such questions.

The next question was also related to the same issue. Participants were asked: (Q\#5) "Do you think discussing societal power relationships, gender and identity issues in the art classroom by means of visuals and objects may cause problems? If so, what problems?" The participants were able to choose as many options as they wanted. The responses showed a distribution as shown in Table 8 below.

Table 8.

Question 5: Do you think discussing societal power relationships, gender and identity issues in the art classroom by means of visuals and objects may cause problems? If so, what problems?

Responses: Causes problems with: $\quad$ f (number of check marks)
With families:
34

\begin{tabular}{ll}
\hline With all of them: & 32 \\
\hline With National Ministry of Education: & 31
\end{tabular}

With students:

\begin{abstract}
None: 1

The participant responses showed that discussions of societal power relationships, gender and identity issues are seen as potentially problematic. The frequency and distribution of responses showed that the issue in question may be problematic for families, Ministry of National Education, students, school administrations, and teachers. Religion-related issues might also be a problem for these groups (Table 8). The table ironically may also represent the power conflicts between social and political institutions. Discussing power conflicts in educational settings may be not possible either because of power conflicts within the
\end{abstract}


agents themselves as shown in Table 8. The VCAE applications and practices may not be easily adapted in such politically polarized societies.

The participants were asked whether they know an art education approach based on issues such as discussing societal power relationships, gender and identity issues in the art classroom by means of visuals and objects? (Table 9).

Table 9.

Question 6: Do you know an art education approach based on issues such as discussing societal power relationships, gender and identity issues in the art classroom by means of visuals and objects?

\begin{tabular}{ccc}
\hline Responses: & $\mathbf{f}$ & $\%$ \\
\hline No response or No (Total) & 69 & 97.2 \\
No response & 32 & \\
No & 37 & \\
\hline Master's student or Master's degree & $(11)$ & \\
Undergraduate degree & $(58)$ & 2.8 \\
\hline Yes and/or Visual Culture Theory (Total) & $\mathbf{2}$ & \\
Master's student or Master's degree. & $(2)$ & $100 \%$ \\
Undergraduate degree & - & \\
\hline
\end{tabular}

The objective of this study was to investigate whether art teachers are informed about VCAE and to what extent they are informed about the VCAE content. The survey responses showed that the overwhelming majority of the participants (97.2\%) were not aware of the educational approach which has VCAE-related content. Only 2 of 71 participants (2.8\%) responded that they knew the approach and it was VCAE. One of these participants had a Master's degree in art education; and the other was a Master's student. It may be inferred that teachers were not informed about VCAE during their undergraduate education. Nevertheless, art teachers at least were expected to provide an answer related to the widely known theories such as Critical Theory or Critical Pedagogy.

Question 7 of the survey: "Do you think discussing societal power relationships, gender and identity issues in the art classroom by means of visuals and objects may serve to a certain ideology or worldview? If so, please explain..." This question aimed at identifying whether art teachers shared the common criticism of VCAE. As previously explained, Visual Culture Theory is claimed to have a Radical Left leaning with a Neo-Marxist hidden agenda. Table 10 shows the art teachers' views of allegedly ideological aspects of VCAE.

Table 10.

Question 7:

Do you think discussing societal power relationships, gender and identity issues in the art classroom by means of visuals and objects may serve to a certain ideology or world view? If so, please explain...

\begin{tabular}{ccc}
\hline Responses: & $\mathbf{f}$ & $\%$ \\
\hline Yes, it serves to a certain ideology or world view: & 69 & 97.2 \\
Master's student or Master's degree & $(11)$ & \\
Undergraduate degree & $(58)$ & 2.8 \\
\hline No, I don't think so (Total): & 2 & \\
Master's student or Master's degree & $(2)$ & $100 \%$ \\
Undergraduate degree. & $(-)$ & $\mathrm{N}: 71$ \\
\hline
\end{tabular}

A very high majority of teachers (97.2\%; 69 participants) responded to this question with "Yes, discussing societal power relationships, gender and identity issues in the art classroom by means of visuals and objects serves to a certain ideology or worldview." Although the teachers were not aware of the existing criticisms against VCAE content, their responses showed that they also viewed this content critically. It may mean that the commonly claimed ideological agenda of VCAE may not be hidden, 
but obviously seen. Conclusively, we may infer that the central authority in Turkey, Ministry of National Education, may not approve such a politically oriented educational approach, and there could be further discussions about its political content. However, a politically Left-oriented ruling party may support and approve of VCAE.

Question \#8 on the survey: "Do you think discussing societal power relationships, gender and identity issues in the art classroom by means of visuals and objects may be approved and seen as an appropriate practice by National Ministry of Education? Explain". Turkish Ministry of National Education is the central government authority, which decides and controls curricula at not only public, but also private schools. Teachers are strictly urged to follow the central curriculum and they are also not allowed to introduce ideological content other than the official governmental ideology. In this sense, it is clear that teachers have certain restrictions when responding to question \#8. The distribution of their responses is shown in Table 11. Their responses may also vary based on "to what extent they think societal power relationships, gender and identity issues are political issues", and, therefore, may cause problems with the official authority (National Ministry of Education).

Table 11.

Question 8: Do you think discussing societal power relationships, gender and identity issues in the art classroom by means of visuals and objects may be approved and seen as appropriate practice by National Ministry of Education? Explain?

\begin{tabular}{lcc}
\hline Responses: & $\mathbf{f}$ & $\%$ \\
\hline No, it would not be approved (Total): & $\mathbf{4 4}$ & 61.97 \\
\hline Master's student or Master's degree. & $(6)$ & \\
Undergraduate degree & $(38)$ & 2.82 \\
\hline Yes, it could be approved (Total): & 2 & \\
Master's student or Master's degree & $(2)$ & 32.4 \\
Undergraduate degree & $(-)$ & \\
\hline No response (Total) & 23 & 2.82 \\
Master's student or Master's degree & $(5)$ & $100 \%$ \\
\hline Undergraduate degree & $(18)$ & \\
\hline Not sure (Total) & 2 & $\mathrm{~N}: 71$ \\
\hline
\end{tabular}

As expected, $61.9 \%$ (44) of the participants supported the idea that (Question \#8) discussing societal power relationships, gender and identity issues in the art classroom by means of visuals and objects may NOT be approved and seen as appropriate practice by National Ministry of Education. On the other hand, although the question is clear, 32.4\% (23) of the participants chose not to answer this question and left it blank. It is important to note that only $2.8 \%$ (2) of the participants thought that it would not be a problem and National Ministry of Education would approve of this practice. One of these two participants speculated that National Ministry of Education would support this practice because their national objective is "to cultivate individuals who question, who think critically, reflectively, and analytically." At this point we need to point out that the National Ministry of Education uses some expressions to identify objectives such as "...questioning, thinking critically, etc. ..." However, these expressions are not directly or solely related to Critical Pedagogy, but rather they refer to analytical and rational thinking, especially within the Enlightenment frame. Critical thinking in its conventional use and this meaning are distant from its conceptual meaning in socio-cultural context and in the Critical Pedagogy.

Table 12 shows the participant responses to survey question \#9: "Do you think that societal power relationships, gender and identity issues should be discussed by means of visuals and objects in the art classroom?" 23.94\% (17) of the participants agreed that societal power relationships, gender and identity issues should be discussed by means of visuals and objects in the art classroom. 7 out of these 17 participants were either graduate students or had a graduate degree (Master's). As previously mentioned, teachers with 
graduate education attainment tend to be informed and think of VCAE-related content more positively and even as necessary in art education. Table 12 also shows figures that confirm this inference.

Table 12.

Question 9: Do you think societal power relationships based on ethnicity should be discussed by means of visuals and objects in the art classroom?

\begin{tabular}{lcc}
\hline Responses: & $\mathbf{f}$ & $\%$ \\
\hline Yes, they should be (Total) & $\mathbf{1 7}$ & 23.94 \\
\hline Master's student or Master's degree & $(7)$ & \\
Undergraduate degree & $(10)$ & 42.25 \\
No, they shouldn't be (Total) & 30 & \\
Master's student or Master's degree & $(1)$ & 30.99 \\
Undergraduate degree & $(29)$ & \\
\hline Not sure (Total) & 22 & 2.82 \\
Master's student or Master's degree & $(4)$ & $100 \%$ \\
Undergraduate degree & $(18)$ & \\
\hline No response (Total) & 2 & $\mathrm{~N}: 71$ \\
\hline
\end{tabular}

Table 13 shows the participant responses to question \#10: Do you think that religion-based societal power relationships should be discussed by means of visuals and objects in the art classroom? In Turkish society, ethnicity and religion are deemed to be sensitive topics of discussion. Especially religion is seen as an individual and personal matter. Therefore, it may not be perceived as an ordinary topic of discussion in terms of typical power dynamics of the society.

Table 13.

Question 10: Do you think religion-based societal power relationships should be discussed by means of visuals and objects in the art classroom?

\begin{tabular}{lcc}
\hline Responses & $\mathbf{f}$ & $\%$ \\
\hline Yes, they should be (Total) & $\mathbf{1 7}$ & 23.94 \\
\hline Master's student or Master's degree & $(6)$ & \\
Undergraduate degree & $(11)$ & 50.70 \\
\hline No, they shouldn't be (Total). & 36 & \\
Master's student or Master's degree & $(5)$ & 22.54 \\
Undergraduate degree & $(31)$ & \\
\hline Not sure (Total) & 16 & 2.82 \\
Master's student or Master's degree & $(1)$ & $100 \%$ \\
Undergraduate degree & $(15)$ & \\
\hline No response (Total) & 2 & $\mathrm{~N}: 71$ \\
\hline
\end{tabular}

Typically, the issue of belief and religion is seen as a sacred, sensitive and controversial matter in Turkish culture. As a deeply rooted societal norm in Anatolia, people from various sects or belief systems have traditionally lived together in harmony for thousands of years; so, they avoid discussing matters of belief that cause controversy and they also avoid it out of respect to each other. On the other hand, VCAE encourages discussion of power relationships on religion and belief basis. In a conventional classroom, issues may arise when the teacher attempts to discuss these culturally sensitive matters of belief. As shown in Table $13,50.70 \%$ (36) of the participants think that discussing religion-based societal power relationships by means of visuals and objects may not be appropriate. The participants who think otherwise are $23.94 \%$ (17); and the participants who responded as "Not sure" are $22.54 \%$ (16). 


\section{Analysis and Discussion}

As previously shown in the Results and Analysis section, the results of the participant responses provided answers to the research questions. Research question \#1: "How much and to what extent are art teachers informed about Visual Culture Theory, its principles and content?" While almost all questions of the survey (1-10, except \#8), aimed to clarify to what extent art teachers are informed about the VCAE and its theoretical principles, each survey question focused specifically on one aspect of the VCAE content, applicability of the content, or the possible issues to be encountered if applied in educational settings. The research questions and the corresponding survey questions are listed below to clarify interrelationships between research questions and survey questions:

Research questions:

1. How much and to what extent are art teachers informed about Visual Culture Theory?

2. What do art teachers think about the applicability of foundational principles of Visual Culture Theory?

3. According to art teachers, what basic principles of the Visual Culture Theory may be problematic in terms of their applications and practices?

Survey question 1 (Table 4): Do you think that societal power relationships and structural hierarchies should be brought into the classroom and discussed? (Corresponding research question 1)

Survey question 2 (Table 5): Do you think that discussions of societal issues of gender, identity and power relationships bring politics into the art classroom? (Corresponding research question 1)

Survey question 3 (Table 6): Do you think that politics should be discussed in the art classroom?

(Corresponding Research Question 1, 2)

Survey question 4 (Table 7): Do you think that societal power relationships, gender and identity issues should be discussed in the art classroom by means of visuals and objects? (Corresponding research questiona 1 and 2)

Survey question 5 (Table 8): Do you think that discussing societal power relationships, gender and identity issues in the art classroom by means of visuals and objects may cause problems? If so, which? (Corresponding research questiona 1, 2, and 3)

Survey question 6 (Table 9): Do you know an art education approach based on issues such as discussing societal power relationships, gender and identity issues in the art classroom by means of visuals and objects? (Corresponding research question 1)

Survey question 7 (Table 10): Do you think that discussing societal power relationships, gender and identity issues in the art classroom by means of visuals and objects may serve to a certain ideology or worldview? If so, please explain... (Corresponding research questions 1 and 2)

Survey question 8 (Table 11): Do you think that discussing societal power relationships, gender and identity issues in the art classroom by means of visuals and objects may be approved and seen as appropriate practice by the National Ministry of Education? Explain (Corresponding research question 3)

Survey question 9 (Table 12): Do you think that societal power relationships based on ethnicity should be discussed by means of visuals and objects in the art classroom? (Corresponding research questiona 1, 2, and 3) 
Survey question 10 (Table 13): Do you think that religion-based societal power relationships should be discussed by means of visuals and objects in the art classroom? (Corresponding research questions 1, 2, and 3)

For instance, question \#6 of the survey (Do you know an art education approach based on issues such as discussing societal power relationships, gender and identity issues in the art classroom by means of visuals and objects?) was directly connected to VCAE conceptual principles in a comprehensive sense. Almost all participants (97.2\%, 69 participants) responded with either 'No' or 'left blank' (Table 9). When we look at how the question was formed, it does not include a direct reference to Visual Culture Theory, but it was structured to epitomize its content and foundational principles (Duncum, 1997; Tavin \& Tervo, 2018). The use of terms 'visual' and 'culture' was likely to cause misunderstandings, since they are conventional words of vernacular (as explained in the analysis section); instead, the questions included direct or indirect meanings attributed to the content of the VCAE. It was also confirmed through the responses to the other questions, which included references to the VCAE content, so it is clear that the participants were mostly not informed about VCAE.

If participants had been asked questions such as "Have you heard of Visual Culture Theory?" or "What do you know about Visual Culture Theory?", their responses would have been different because of the explained reasons. In this case, because of the misunderstanding they would have responded that they incorporate visual culture content in their curriculum. In such a situation, internal validity measures would have been affected negatively. However, the results showed that almost all participants, even the recent graduates, were not informed about VCAE. The participant responses showed that teachers are mostly not informed, and it is worrisome if VCAE is still not covered in the teacher education curriculum, whereas it is one of the two major art education theories of the last 40 years.

Mamur (2012) studied visual culture dialogues with pre-service art teachers and applied Duncum's Seven Principles (Duncum, 2010, pp. 6-10). The study focused on visual phenomena within power dynamics through criticisms of consumer society and corporate capitalism as expected from Critical Theory based practices (pp. 2171-2172). In VCAE practices, we often see that Marxist and Neo-Marxist aspects went incognito, criticisms rather mostly focused on the uses of media as tools of marketing strategies in consumer societies. In addition, we frequently see a public confusion between concepts of 'Critical Theory' and 'Critical Thinking'. Critical thinking is a necessary skill especially for creative thinking process, while Critical Theory is a political theory and critical pedagogical interventions are connected with the second one. They are not synonymous although they might be related at some points. This common confusion seems to be serving to a specific purpose as a useful tool for a hidden NeoMarxist agenda, especially in educational settings. There may be a need to study political theories to understand and analyze sociological power relationships in the society to clarify philosophical and ideological aspects of educational theories and practices.

Research question \#2: "What do art teachers think about the applicability of foundational principles of Visual Culture Theory?" The survey questions 3, 4, 5, 7, 9, and 10 correspondingly aimed at finding an answer to the research question \#2. The aspects considered in various questions were:

- Bringing in and discussing the societal power structures and dynamics into the classroom;

- Discussing gender identities and ethnicity in the classroom based on political perspectives;

- Discussing religion-based societal power dynamics in the classroom;

- Possible problems and concerns regarding the applications of these core dimensions of VCAE. 
The analyses of item responses showed that teachers perceive ideologically oriented approaches such as VCAE as problematic. Art teachers acknowledged that discussion and interpretations of visuals and objects within socio-political perspectives would cause problems and complications, especially in a highly politicized country with divided political factions (Table 10).

The recent research conducted in Turkey is consistent with the findings of the current study. In a recent study (Özsoy, et al., 2020) about teacher opinions in Turkey, VCAE applications, practices and the encountered difficulties and problems were investigated. The teachers considered aspects such as perception, critical thinking, deep and independent thinking to apply in VCAE practices during the study (Özsoy et al., 2020, p. 784). Teachers also reported anticipated issues to be encountered during VCAE practices. As consistent with the earlier discussions and other studies (Mamur, 2012, p. 2172), teachers reported concerns related to teacher competencies and the difficulty of identifying the relevant disciplines of visual contexts during VCAE practices (Özsoy, et al., 2020, p. 785). Although they anticipated and reported various issues and concerns related to VCAE applications and practices (i.e., class duration, classroom size) (Özsoy, et al., 2020, p. 785), they did not report any concerns related to issues such as societal power dynamics, gender and ethnic identity issues, religion-based power dynamics. These issues are the core and differentiating dimensions of the VCAE based on the literature and it is obvious that sociological and political aspects of the VCAE should also be included in the further studies. Political theories should also be a part of teacher training programs for comprehensive VCAE classroom practices. The teachers were also concerned about the possible interference by school administrations. It might also be expected that this concern will further increase once teachers learn about the highly debated political core dimensions of the VCAE.

In another study with elementary students, visual arts practices were designed based on the VCAE in an action research. However, the study (Türkcan \& Yaşar, 2011) neither focused on nor suggested any concerns regarding power-related principal characteristics of the VCAE. In fact, in Turkey it is a common understanding of VCAE that most practices are based on working with technology, media, popular culture elements, and everyday visuals, but not focusing on the controversial characteristics of power dynamics in relation to the visual phenomena. It might be the reason why practitioners are not aware of political aspects of the VCAE which were clearly defined and firmly debated throughout the VCAE literature. The common visual culture practices may also be comparable to viewing Andy Warhol works (i.e., Brillo Boxes and Pop-Culture based artworks) as promoting consumerism and capitalism. However, as we all know it has deeper and more meaningful connections; in fact, he is the favorite artist of a postmodern art critic, Arthur Danto. Andy Warhol and his works epitomizes the critiques of capitalism from Critical perspectives. It seems rather a necessity that political theories in relation to Art Education paradigms should be a part of art teacher training programs.

Research question \#3: "According to art teachers, what basic principles of the Visual Culture Theory may be problematic in terms of their applications and practices?" The survey questions 5, 8, 9, and 10 correspondingly aimed at finding an answer to the research question \#3. The responses to the related questions showed that teachers think that bringing socio-cultural views and perspectives into the classroom may be appropriate. On the other hand, discussing religion and power relationships without hurting any sensibilities does not seem possible (Table 13). Another puzzling matter of VCAE similar to religion and belief is ethnicity and power relationships. The participant teachers consider ethnicity and power issues as socially and politically sensitive matters, and do not advocate bringing them into the classroom (Table 12). Whereas ethnicity issues could be viewed as part of democratic diversity, discussing ethnic issues in the classroom within controversial Critical Theory perspectives may cause further problems. The VCAE content as an educational approach was perceived as likely to cause problems with families, the National Ministry of Education, school administrations and teachers (Table 8). As we all know, social and cultural views and perspectives 
are already being considered in conventional art education practices; however, VCAE is a controversial approach which brings ideological discourses into the classroom. Though bringing diverse perspectives into the classroom is necessary to construct a healthy democratic society, many art teachers do not think that the society and the educational system are ready for such conflicting approaches. Teacher responses show that VCAE-related perspectives need to be examined within the specific conditions of Turkey. Conclusively, the VCAE applications and practices in Turkey seem controversial and may encounter certain restrictions (Table 11).

In a recent study, Mamur (2020) explored the aesthetics and cultural texture of shopping malls through critical analysis. In the study teachers were invited to think about sustainability through visual culture pedagogy. As the final remarks in the study, it was suggested that "for sustainable development, there were various topics that can be discussed with different approaches such as social justice, social judgments, sustainable democratic society, and gender equality that can be associated with visual culture pedagogy apart from consumption habits" (p. 24). Please note that the specified issues affirm the major controversial discussions (i.e., Antonio Gramsci's theories of Cultural Hegemony) previously mentioned throughout the paper (Jasa, 2020; Lehmann, 2018; Peterson, 2018). Some of these issues are social justice, gender-identity politics, egalitarianism, and open society.

\section{Conclusions and Recommendations}

As an educational theory to bring in diverse views for a democratic society, the VCAE is claimed to have a hidden Neo-Marxist agenda. Although there have been discussions and direct accusations toward VCAE's ideological agenda, participants of this study seem unaware of all these discussions. Nevertheless, they have a hunch or they simply connect the puzzles and they think that basic principles of VCAE serve to a certain ideology and worldview (Table 10). Nonetheless, there were no questions in the survey asking participants what particular ideology VCAE may be traced back to. Future qualitative studies may focus more on contentrelated debates about VCAE. Educational research and interventions in Turkey have extensively focused on the empirical practices. Educational philosophies in relation to theories should be extensively discussed and investigated by professionals. Understanding and structuring new theories may not be possible without debating trending theories in the academia. This study was designed as a descriptive survey and no questions were asked regarding the debated aspects of studio applications of VCAE. We may conclusively say that VCAE is still almost an unknown phenomenon among participant teachers. We may perhaps not expect wellinformed discussions about the VCAE content yet.

Despite the academic efforts and increasing examples of VCAE practices, there will be more reactions and feedback so that we will be able to pinpoint problems regarding VCAE applications. The Discipline-Based Art Education (DBAE) is a widely known educational approach, and it has been extensively debated and criticized over the years. Beyond DBAE, approaches such as Visual Culture Theory and Science, Technology, Engineering and Arts should also be widely known so that we may be able to discuss, compare and adapt new practices. In this endeavor, the discussions should go beyond academics and graduate students; art teachers also as primary practitioners should partake in the discussions actively.

It is obvious that adapting an educational model without discussing pedagogical interventions, practices, social, ideological, and philosophical aspects is likely to cause problems. Explaining the rationale of a new educational theory to the policy makers will also be difficult. Educational models so far emerged as solutions to the problems of the Western systems. We may need to be able to develop theories and applications unique to our own cultural standing, and addressing our unique problems. The DBAE was simply an academic approach to facilitate otherwise sophisticated field of art education. Considering its content and debated aspects; the VCAE goes beyond being a new paradigm, it is accused of being a Retro-Marxist approach 
resulting from postmodernist turbulences. When examined closely, it is difficult not to see the connections between the VCAE and Karl Marx's ideas about alienation and his 'Conflict Theory' (Lehmann, 2018). There have been a confusion between the casual uses of 'critical thinking' and 'Critical Theory'. This study also showed that a similar confusion exists between the casual phrases 'visual culture' and 'Visual Culture in Art Education'. Moreover, seemingly egalitarian approaches to destroy the elitism of Fine Arts and Academic Art are questionable as they also remind us another destructive Cultural Marxist strategy disguised as postmodernism (i.e. Gramsci's theories).

Yılmaz et al. (2019) investigated the relationship between social learning and visual culture. They clarified and formulated the term 'visual culture' as an effective social learning tool and a vehicle in social learning process, especially vicarious experiences. Nevertheless, they did not make any connections with societal power relationships within visual cultural dimensions. The social learning models through visual culture as they suggested could also be studied within other aspects such as how they are used to shape individuals' belief systems and further used to build and indoctrinate world views and ideologies. Today, a Visual Arts course is commonly seen as a class without a purpose, a class which includes only visual-decorative practices, a class philosophically not profound and without academic content. Nonetheless, apart from its ideological considerations VCAE offers value. The VCAE may transform Visual Arts classes into a class which creates an awareness in a consumer society; a class in which deep social, cultural and political discussions take place. Consequently, we may face a new problem of teacher training; approaches such as VCAE will require teachers with a higher intellectual potential, and extensive training in diverse fields such as sociology, history, politics, and anthropology. 


\section{References}

Boughton, D. (2004). The problem of seduction: Assessing visual culture. Studies in Art Education, 45(3), 265-269.

Chalmers, G. (2005). Visual culture education in the 1960s. Art Education, 58(6), 6-11

Creswell, J. W. (2014). Research design. Los Angeles: Sage.

Duncum, P. (2010). Seven principles for visual culture education. Art Education, 63(1), 6-10.

Duncum, P. (2009). Visual culture in art education, circa 2009. Visual Arts Research, 35(1), 64-75.

Duncum, P. (2003). The theories and practices of visual culture in art education. Arts Education Policy Review, 105(2), 19-25.

Duncum, P. (1997). Art education for new times. Studies in Art Education, 38(2), 69-79.

Duncum, P. (1987). What, even Dallas? Popular culture within the general art curriculum. Studies in Art Education, 29(1), 6-16.

Duncum, P. (1982). Toward locating children's spontaneous drawing during middle childhood within art education. Journal of the Institute of Art Education, 6(1-2), 69-86

Dutton, D. (2009). The Art Instinct: Beauty, pleasure and human evolution. New York: Bloomsbury Press.

Dutton, D. (2013). Aesthetics and evolutionary psychology. In J. Levinson (Ed.). The Oxford Handbook of Aesthetics (pp. 693-705). Oxford: Oxford University Press.

Efland, A. (2005). Problems confronting visual culture. Art Education, 58(6), 35-40.

Fraenkel, J.R. \& Wallen, N. E. (2000). How to design and evaluate research in education. New York: McGraw Hill.

Heise, D. (2004). Is visual culture becoming our canon of art? Art Education, 57(5), 41-46.

Jasa, J. (2020). The Dangers of Cultural Marxism to Europe. Retreived 29.08 .2020 from https://www.youtube.com/watch?v=ACyLMJOY0wM\&list=PL2XZFDA4TkUZZeGXK0IW8V6mPkg4rdkGV\&index=2\&t=19 $2 s$

Lehmann, C. (2018). What is Marx's 'Conflict Theory' doing to our politics? YouTube video: https://www.youtube.com/watch?v=9xAvkJpm7Nk\&list=PL2XZFDA4TkUZZeGXK0IW8V6mPkg4rdkGV\&index=13, Access date: February 4, 2021.

Mamur, N. (2012). Perceptions concerning visual culture dialogues of visual art pre-service teachers. Educational Sciences: Theory \& Practice, 12(3), 2166-2173.

Mamur, N. (2020). A critical analysis of aesthetics and cultural texture of shopping malls in teacher education: The ideology of space. International Journal of Education \& the Arts, 20(27). http://doi.org/10.26209/ijea21n27

Merriam-Webster Online Dictionary. (2021). Enculturation. Retrieved 13.03.2021 from https://www.merriamwebster.com/dictionary/enculturation

Özsoy, V., Mamur, N., \& Sarıbaş, S. (2020). Use of visual culture in visual arts courses: Opinions of participating teachers after TUBITAK-4005 Project. Pegem Eğitim ve Öğretim Dergisi, 10(3), 767-808.

Pariser, D. (2019). Dead cat, living horse: Losing our heads over theory. Studies in Art Education, 60(1), 69-74. 
Peterson, J. (2018). Postmodernism in a nutshell - Jordan Peterson. Retrieved $29.08 .2020 \quad$ from https://www.youtube.com/watch?v=el6TVEMnS3E

Smith, R.A. (2005). Efland on the aesthetic and visual culture: A response. Studies in Art Education, 46(3), $284-288$.

Stanford Encyclopedia of Philosophy. (2020). Karl Marx. Retrieved 13.03.2021 from https://plato.stanford.edu/entries/marx/

Tavin, K. \& Tervo, J. (2018). How soon is now? Post-conditions in art education. Studies in Art Education, $59(4), 282-296$.

Thompson, C. M. (2003). Kinderculture in the art classroom: Early childhood art and the mediation of culture. Studies in Art Education, 44(2), 135-146.

Türkcan, B., \& Yaşar, Ş. (2011). The role of visual culture studies on primary school students' interpretation of visual world. Educational Sciences: Theory \& Practice, 11(3), 1564-1570.

Yılmaz, M., Yılmaz, U., \& Demir-Yılmaz, E. N. (2019). The relation between social learning and visual culture. International Electronic Journal of Elementary Education, 11(4), 421-427. 